\title{
تأثير المعرفة المحاسبية على القيادة الاستراتيجية للمنظمة
}

الباحثة: أسماء نعمان جاسم

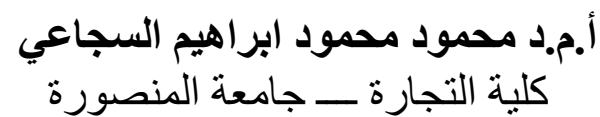

المستخلص

هدفت الدراسة إلى التعريف بكل من مفهوم المعرفة المحاسبية وأنواعها ومكوناتها، فضلاً

عن مفهوم القيادة الاستراتيجية للمنظمة، وبيان أهمية ودور المعرفة المحاسبية في دعمها،

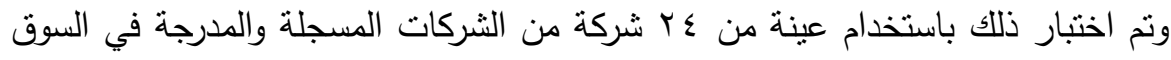

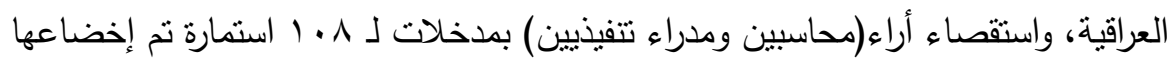

للتحليل الإحصائي من خلال البرنامج (SPSS V.22) وتوصلت الدراسة إلى عدة نتائج

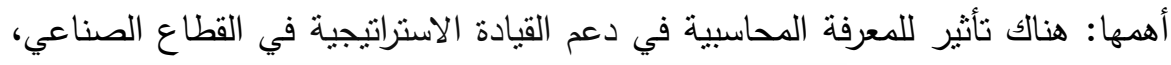

إذ نم التأكيد على أن للمعرفة المحاسبية المتمنلة بالابتكار والتعليم والخبرة والمهارة

والجوانب الفنية والعلمية والتطبيقية والإعلامية دور فعال لدعمها وبما يتلاعم مع متغيرات

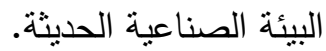

\begin{abstract}
This study aims to define the concept of knowledge, its types and administration, and the concept of accounting knowledge and its components, in addition to the concept of strategic leadership for the organization, besides showing the importance and role of accounting knowledge in supporting it, and this has been tested by using a sample consists of 24 companies of listed companies in Iraqi stock market, and surveying the views of (accountants and executive manages) with inputs to 108 forms which have been subjected to statistical analysis by using SPSS v.22. The study concluded multiple results, the most important ones: there is an impact of accounting knowledge on enhancing the strategic leadership in the industrial sector, it is confirmed that the accounting knowledge is represented in innovation, education, experience, skill and technical, scientific and informative aspects, have an effective role in enhancing it in accordance with the variables of modern industrial environments.
\end{abstract}




\section{طبيعة ومشكلة الاراسة}

برز دور المعرفة المحاسبية بصورة أكثر وضوحاً في ظل التغيرات المعاصرة في المنظمات وبيئتها والتي تتطلب معلومات وخبرات وكفاءات تتلاءم مع هذه المتغيرات،

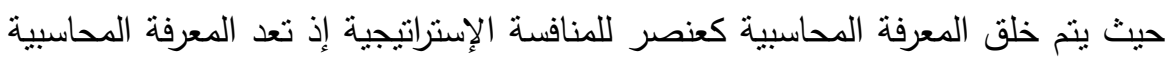
في هذا الثأن أكثرها أهمية وتعتبر مرتكزاً أساسياً لتفعيل أداء المنظمات وتحسينه والوصول إلى الأداء المتميز الذي يمثل قدرتها على تحقيق أهدافها من خلال استخدام الموارد المتاحة بطريقة كفؤة وفعالة، فالقيادة الإسنراتيجية للتعلم، نظهر إلى أي مدى يقوم التهاء

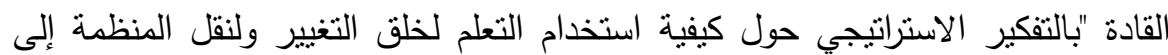
اتجاهات جديدة أو أسواق جديدة، مع نوظيف المعارف والخبرات للقيادة. عليه يمكن تحديد مشكلة الدراسة بالتالي: 1 - هل هناك علاقة ارتباط بين المعرفة المحاسبية والقيادة الاستراتيجية r-هل هناك أثز ذو دلالة إحصائية للمعرفة المحاسبية على القيادة الاستراتيجية

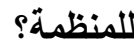

هدف الدراسة

$$
\text { تهدف الدراسة إلى التعريف بكل من: }
$$

1-مفهوم المعرفة المحاسبية وأهميتها وخصائصها ومكوناتها. r-مفهوم القيادة الاستراتيجية للتعلم وعلاقة ودور المعرفة المحاسبية في تدعيم كفاءة هذه وهنها

تتبع أهمية الدراسة من أهمية المعرفة المحاسبية، كونها تمثل موضوعاً حبوياً يساعد في بناء وصياغة أغلب الخطط الإستراتيجية لمتخذي القرار، ويساهم بشكل فاعل اهن

في تعزيز القيادة الاستراتيجية كخاصية لمنظمات الأعمال لاسيما المتعلمة منها. 
ولغرض النحقق من فرضيات الدراسة وتحقيق الأهداف الحددة لها فقد تم تقسيمها إلى

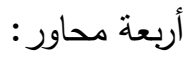

1-المعرفة المحاسبية مفهومها وأنواعها وأهميتها. ب- بفهوم القيادة الاستراتيجية للتعلم في المنظمة وعلاقة المعرفة المحاسبية بها لرفع كفاءة

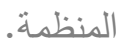

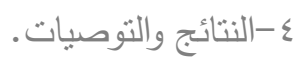

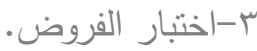

1- المعرفة المحاسبية مفهومها وأنواعها وأهيتها.

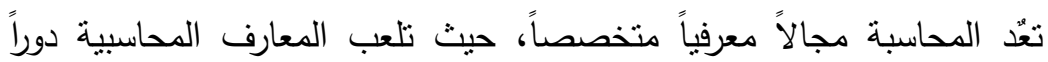

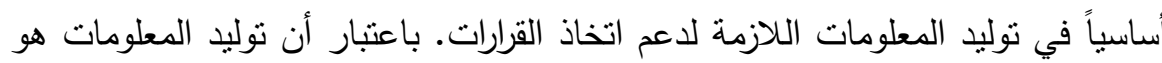

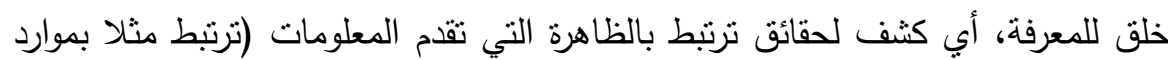

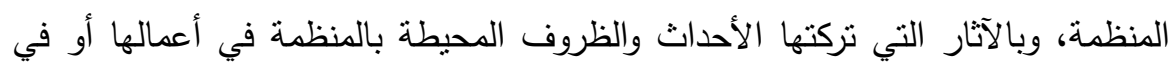

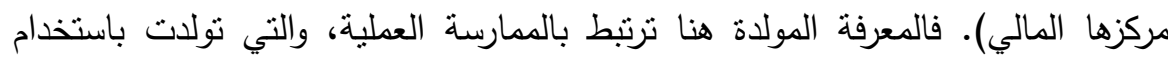

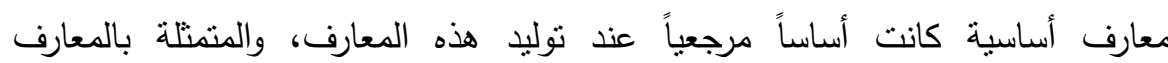

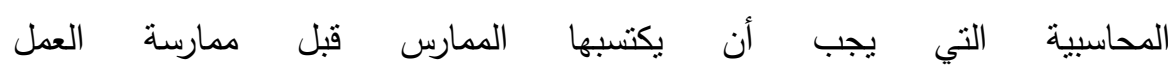

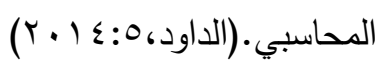

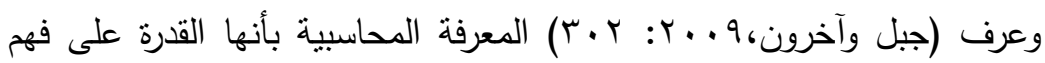
وتفسير المعلومات المحاسبية بالثكل الصحيح ومن ثم اتخاذ القرارات الرشيدة الكفيلة بتطوير نثاط المنظمة. كما أن المعرفة المحاسبية تتكون من مجموعة معارف تراكت عبر مراحل

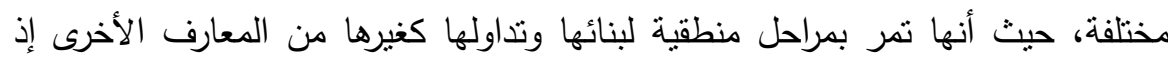

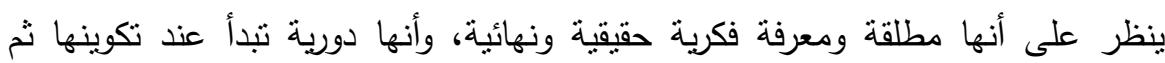

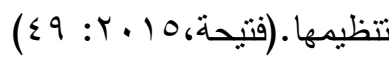

وترى الباحثة انه بمكن تعريف المعرفة المحاسبية بأنها: مزيج من المعلومات

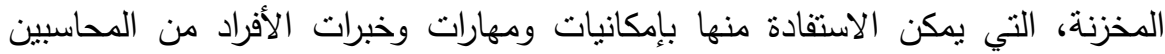

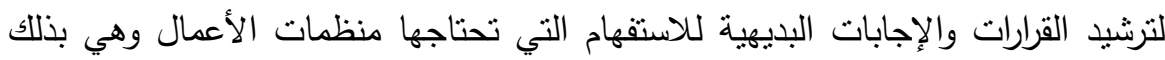
تعّد رأس مال فكري يضيف قيمة للمنظمة. 
1/1/إدارة المعرفة المحاسبية

إن عملية إدارة المعرفة في مجال المحاسبة من شأنها تغيير العمليات الخاصـة بالمنظمة تغيير جذري ولها اهمية قصوى لدعم القيادة وثقافة تبادل المعرفة بأعادة النظر وتحسين ممارساتها الحالية في تحديد اهداف هذه المنظمة، كونها جزء من مبادرات ادارة المعرفة (Salleh et al., 2012:169). ونظراً لأهية دور المحاسبين في المنظمة فأن إدارة المعرفة المحاسبية تلعب دوراً هاماً في توجيه المعرفة والمهارات المهنية في إعداد وعرض المعلومات عن القرارات المالية

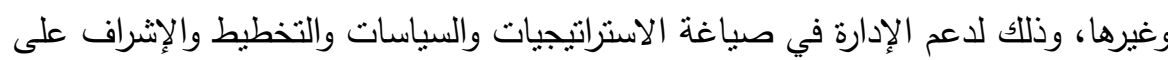
عمليات المنظمة(Gornjak, 2014: 1353). وتخلص الباحثة إلى تعريف أدارة المعرفة المحاسبية بأنها مجموعة من الممارسات والأنشطة المختلفة والتي تعمل على توليد، خزن، توزيع، وتطبيق وابتكار

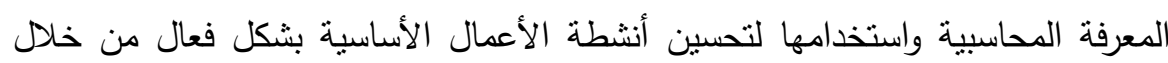
المحاسبين وخبراء المحاسبة الإدارية، لاتخاذ القرارات وحل المشكلات التي تواجهه المجالات الوظيفية والتتظيمية. | ب/أنواع المعرفة المحاسبية وللمعرفة المحاسبية عدة مكونات بنوعيها الصريحة والضمنية وتتمثل في:

1/ ا المعرفة المحاسبية الصريحة

وتتعلق بالمعلومات المحاسبية الموجودة والمخزنة في أرشيف المنظمة وسجلاتها، وفي الغالب يمكن للأفراد داخل المنظمة الوصول إليها واستخدامها.

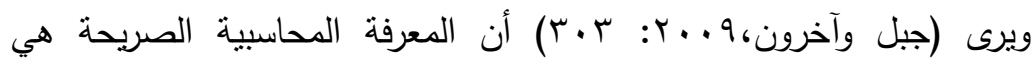
المعلومات المتاحة والمفهومة والتي تحددها خصائص المعلومات المحاسبية، ولقد استعان بما قدمه مجلس معايير المحاسبية الدولية (IASB)عن خصائص للمعلومات المحاسبية المفيدة، والتي تتمنل بـ الملاعمة (وثثقة الصلة)، الموثوقية (الاعتمادية)، قابلية المقارنة، وإمكانية الفهم. كما وتتمنل بقواعد الاعتراف والقياس والتقرير عن المعاملات والتقرير عن الأحداث التي وقعت في شكل قوائم مالية، ومن الجدير بالذكر أن معرفة متخذ القرار بهذه القواعد 


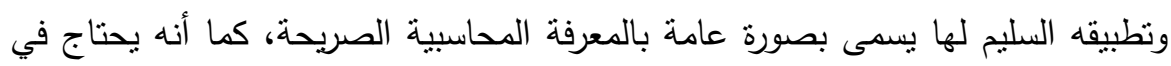

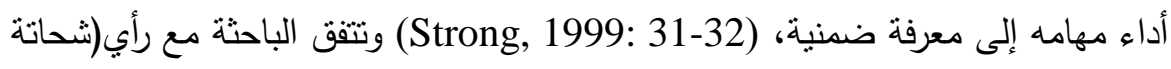

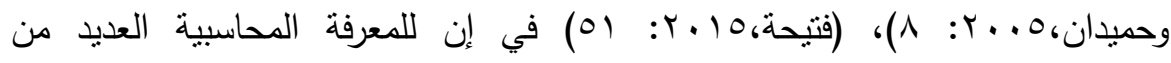
المكونات وبالتحديد (الجوانب الفنية، الجوانب العلمية، الجوانب التطبيقية، الجوانب الإعلامية) فيما يخص الصريحة منها، لذا فان مكونات المعرفة المحاسبية الصريحة يمكن

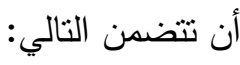
- الجوانب القنية : التحديد، الاعتراف، القياس

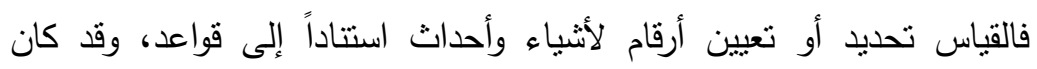

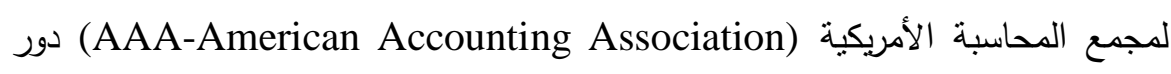
بارز في بلورة الجوانب الفكرية لعملية إثبات. فقد ورد في الثقرير الصادر عن هذا المجمع

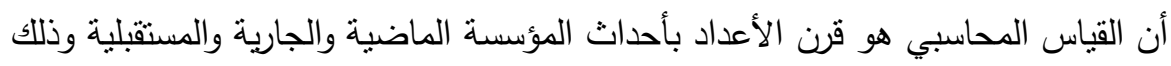

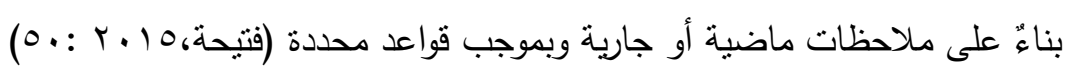

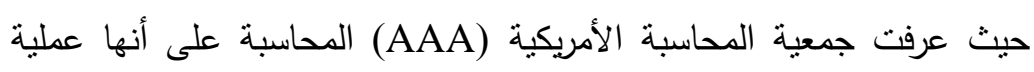
تحديد وقياس وتوصيل المعلومات الاقتصادية ليتمكن المستقيدون من التصرف في ظل الت رؤية واضحة، وان خدمات المحاسبة الواسعة في فروع المحاسبة المالية والتذقيق تهتم بالتحديد والقياس والتسجيل والعرض، بغرض تحديد أعمال المنظمة وتصوير مركزها

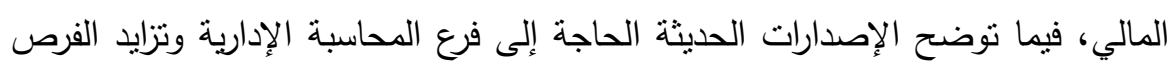
أمام أصحاب مهنة المحاسب الإداري في إضافة القيمة في خدمتها للمنظمة. (البزور

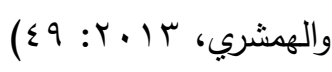
- الجوانب العلمية: المبادئ والمعايير المحاسبية

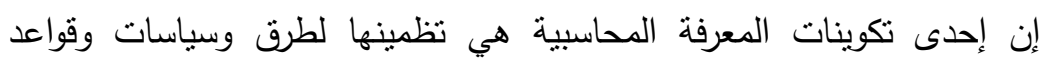
وأسس ومبادئ ومعايير لتقديم وإنتاج المعلومات المحاسبية، ويعرف (Kohler,1970)

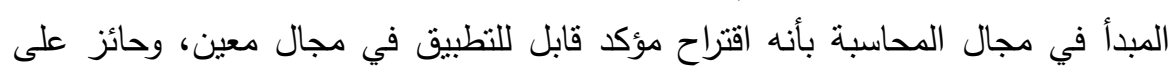

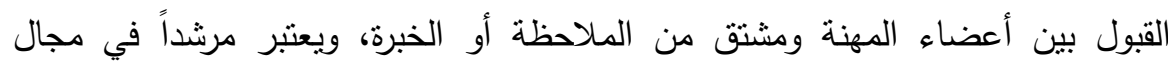
الاختيار بين البدائل التي تحقق الغرض المستهدف من النشاط. وعرفه (الناغي) بأنه حقيقة أساسية تعبر عن ظاهرة معينة أو تعبر عن علاقات بين مجموعة من الظواهر في 
مجال المحاسبة، وهو ليس مطلقاً ولكنه يعبر عما يجب أن يكون عليه التنفيذ.(الناغي (r) $: Y \cdot 116$

وبصورة عامة ينم إحكام عمل المبادئ من خلال القواعد المحاسبية المتمثل بالمعايير المحلية والدولية وتعرف المعايير بأنها نماذج أو إرشادات عامة تؤدي إلى توجيه

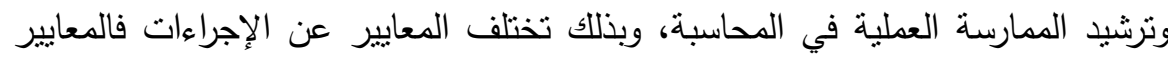
لها صفة الإرشاد العام أو التوجيه بينما نتتاول الإجراءات الصيغة التتفيذية لهذه المعايير

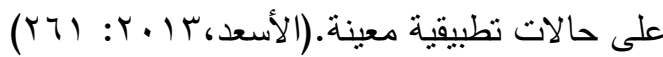
وخلاصة القول أن صياغة المبادئ بصورة نهائية وتعميمها يجب معرفة واختبارئار قدرتها على التطبيق كونها بمثابة قانون عام يمنل الظاهرة موضوع البحث، فيما يعتبر المرشد للتصرف والمقارنة المعيار منل مقارنة مستويات إعداد التقارير • - الجوانب التطبيقية: الإجراءات المالية تتمثل الإجراءات التطبيقية بالخطوات التي يتبعها المحاسب أثناء تطبيق قاعدة معينة لتحقيق هدف تطبيق القياس أو التوصيل في المجال المحاسبي، والإجراءات

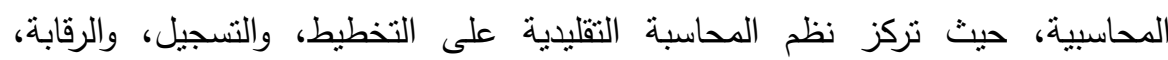
Schiller, ) والتحليل، ونوفير المعلومات، عن العطليات الرئيسية (الدورة المحاسبية) .(2010: 129

كما ويشير الإجراء إلى ما يقوم به الدحاسب وعادة يناسب حالة معينة وفي ظروف خاصة دون حالة أخرى كما انه قد لا يناسب نفس الحالة مع اختلاف الظروف، لهاء

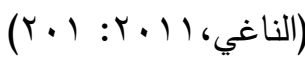

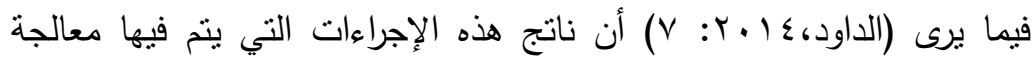

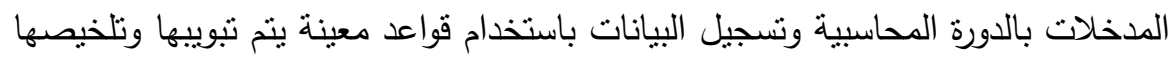
حتى يتم الحصول على الخلاصة بالأرصدة النهائية لهذه الأحداث وتعتبر هذه النتائج من قوائم وتقارير مخرجات عملية لنظام محاسبي وهي مدخلات لنظام القرار لمستخدمي

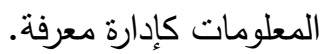
- الجواتب الإعلامية: الإفصاح المحاسبي 
يشير الإفصاح إلى الكثف عن النتائج والمعلومات المالية في القوائم المالية المنشورة. حتى يمكن الاعتماد عليها في اتخاذ القرارات المتتوعة من قبل الأطراف المستفيدة. ويُعد الإفصاح المحاسبي جوهر نظرية المحاسبة، فقد أزداد الاهنمام به، وعلى الهي نحو خاص بعد نوسع نشاط المنظمات، وارتبط هذا التطور بالقوائم المالية التي تعد بلهن مخرجات لنتائج نشاط هذه المنظمات، لتصبح الأساس الذي يعتمد عليه في اتخاذ القرارات

.(Abdelsalam \& Weetman, 2007: 75)

وعلى الرغم من قدم الاهتمام بموضوع الإفصاح المحاسبي إلا أن الاهتمام بـ

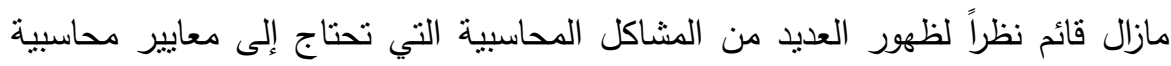
تساعد المنظمات في قياس العناصر المرنبطة بها والإفصاح عنها، لذلك يحظى الإفصاح

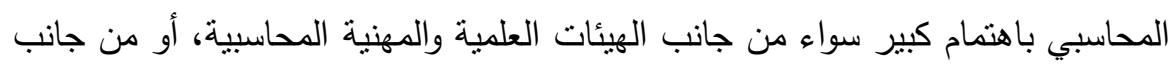

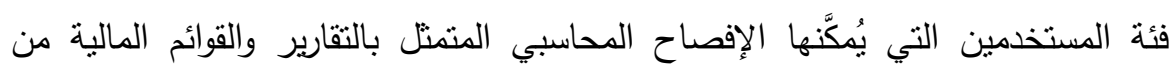

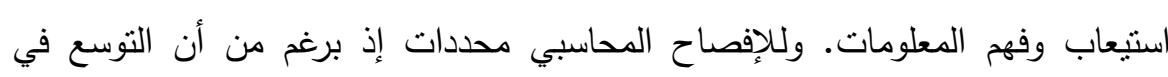
الإفصاح المحاسبي يساعد المستخدمين للقوائم المالية في اتخاذ القرارات المناسبة، إلا أن

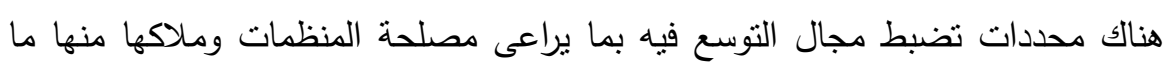

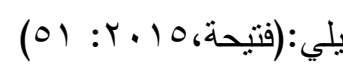
- يجب أن تعبر المعلومات المقدمة عن نتائج أعمال المنظمة عما حدث فعلاً وبما تؤيده القوانين والتعليمات التي تحكم عمل المحاسب في عمله. - تقليص وضغط مقدار المعلومات المفصح عنها لاعنبارات موجبة تتعلق بعبء المبله المعلومات المراد الإفصاح عنها. - أن تكون العوائد المتوقعة على أساس المخاطرة من الإفصاح منطابقة من وجهة نظر كل

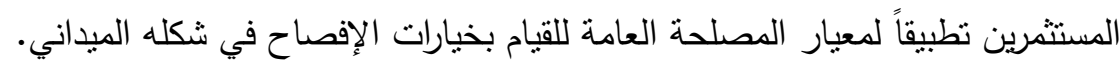
- تحديد طبيعة المعلومات التي يجب أن تكون متاحة للآخرين من قبل إدارة المنظمة بما

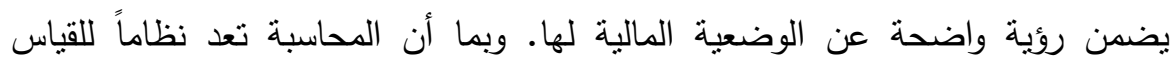

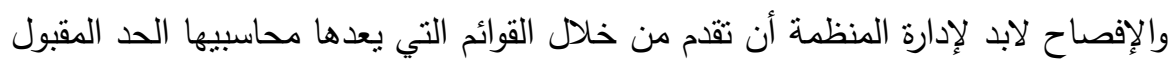
للإفصاح عن ما تحويه أرقامها المحاسبية في القوائم المالية.

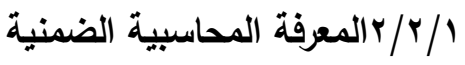


تمنل المعرفة المحاسبية الضمنية العنصر الثاني للمعرفة المحاسبية الذي يضم الخبرة والانطباعات عن الحسابات، وهي أكثر صعوبة لتراكمها من خلال سنوات الخبرة

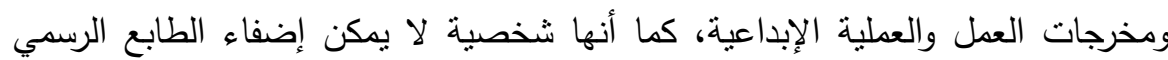
عليها ولا يمكن تبادلها(Pitzer, 2007: 22). ويمكن أن تتنمل المعرفة المحاسبية الضمنية على المكونات التالية:

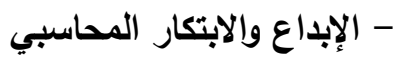
تحظى المحاسبة بتطور معرفي منواصل إذ يمكن للمحاسب أن يبدع في مهيته

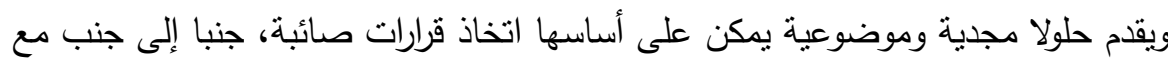
الإبداعات في المهات والوظائف الأخرى. وبشكل عام يعرف الإبداع لغوياً بأنه إنشاء الثيء أو بدعه، أو الإيجاد أو أو أوات

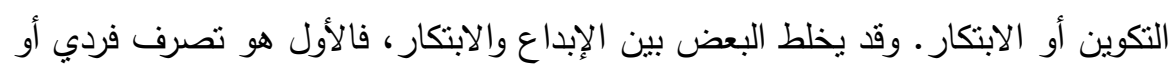
شخصي مصدره عقل الفرد نفسه، في حين أن الابتكار هو عملية جماعية يتخخل فيها

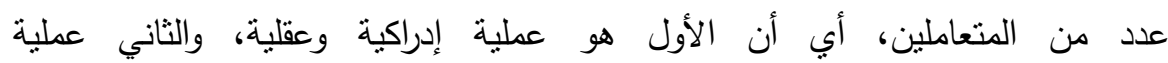

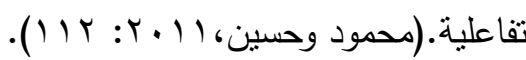
ولا شك أن هناك إبداعاً متواصلاً في تطور المحاسبة ومهنتها، وما تتوع وتطور فروع المحاسبة إلا نتيجة إنباع الأساليب والمناهج العلمية وتتوع فروع المحاسبة جاء دلئ دليلاً على ذلك.

لذا فالإبداع المحاسبي هو استخدام أساليب أو إجراءات أو مفاهيم أو معايير أو

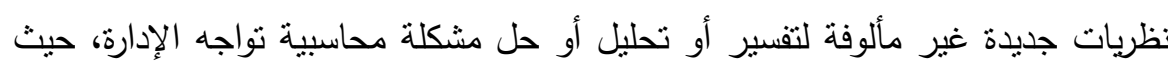
يتمتع المحاسب المبدع بقدرات مميزة، من استتعار للمشكلات وتحديد صعوبتها وبيان طبيعتها، والبحث عن الحلول وإجراء التخمينات أو الافتراضات عن الخلل، واختيار

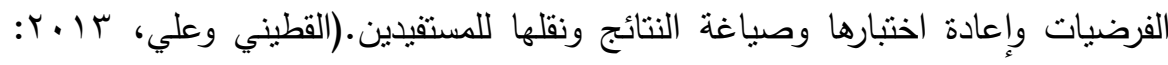

تتمثل بمزيج المعارف والمهارات التي يمنلكها المحاسب والتي يسخرها بأداء العمل بأعلى مستوى من الكفاءة. إذ أن المهارة هي اكتساب والاحتفاظ وتتظيم وصيانة 
الملفات وتقييم البيانات وتفسير وتوصيل واستخدام معلومات الحوسبة، ففهم النظم

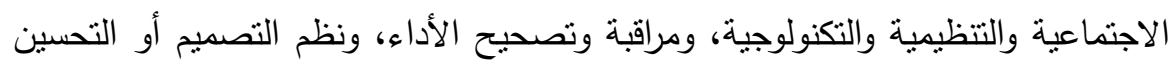

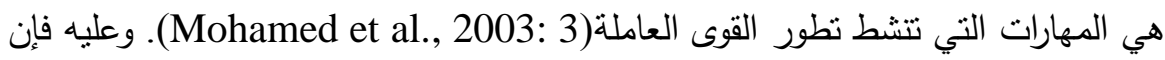
تطوير مهارات ومعرفة المحاسبين باستمرار ستعزز الاحتراف المحاسبي للمنظمة، وتعد

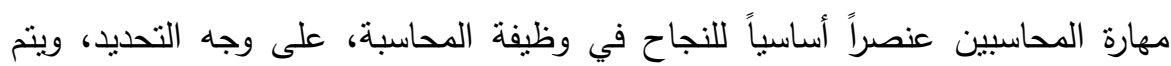
تحسين مهارة المحاسب من خلال التحسين المستمر لـهارة ومعرفة وقدرة المحاسبين(Salakjit \& Phapruke, 2011: 159).

حيث يقوم المحاسب الإداري بتطوير المهارات المهنية الخاصة به، والتي تمثل

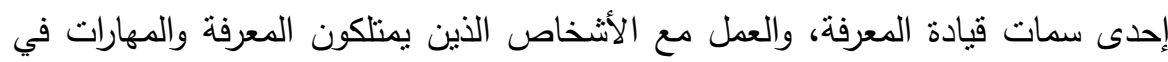
تقديمها، ويستمع إلى الآراء ويقوم بتقييم الأفكار، كما يسعى لتوليد المعلومات المحاسبية

الخاصة بالمعرفة والمهارات اللازمة للمنظمة في المستقبل(Bozdogan, 2013: 127). - الخبرة المحاسبية تتمثل الخبرة بالمعرفة المتولدة لاى المحاسب نتيجة الممارسة وتتوع الأنشطة التي يقوم بها وتكرارها لمرات عدة. إذ أن المهام الرئيسية في التطبيق تعكس قدرة بالثرة

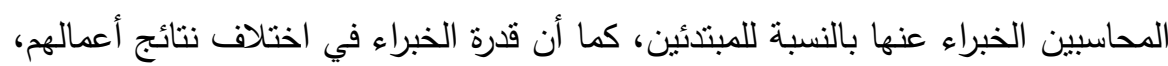
من تتظيم المعرفة وتطوير إجراءات أكثر فعالية لتطبيق تلك المعرفة لهذه المهية. مرة بهاء

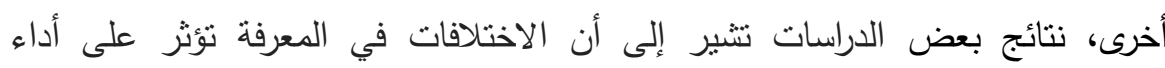
المحاسب في مهامه( Anany, 2011:80).

وتعد الخبرة مكون من مكونات المعرفة المحاسبية التي إذا نم استعمالها استعمالاً

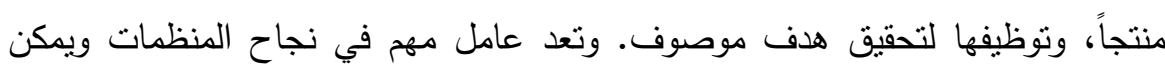

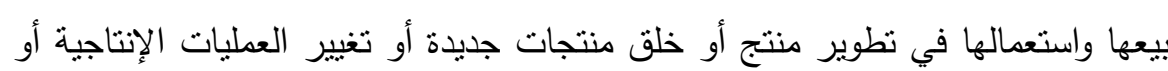

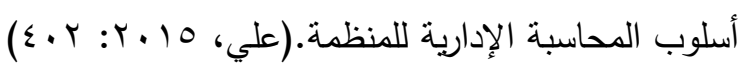
ويشير (Chong, 2011: 510) إلى أنه يجب نوثيق وتبادل المعرفة المحاسبية الضمنية المنقولة إلى الصريحة من خبرات المحاسبين ذوبي المهارات الفردية، التي تم الحصول عليها من الدوران الوظيفي وكذلك المصادر الأخرى. فهذا بشكل خاص حاسم دئ دأ للمعرفة الضمنية أو الحاسمة للمهمة بما أنها المحدد الرئيسي لجودة اتخاذ القرار وتحسين لأنئ 
الأداء التتظيمي. في حين أنه يمكن لنظم المعلومات أن تلعب دوراً لنقل المعرفة الضمنية والصريحة. إلا أن الأسلوب الأمتل لنقل المعرفة الضمنية ليست من خلال قواعد اليبانات

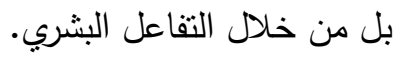

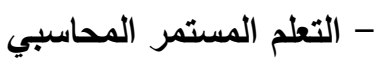

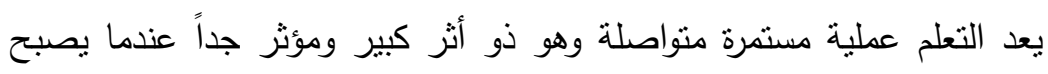

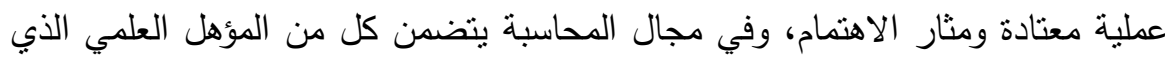

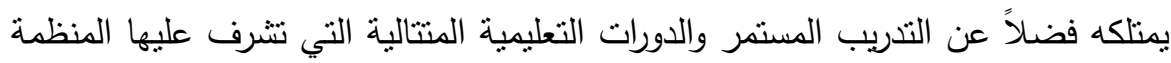

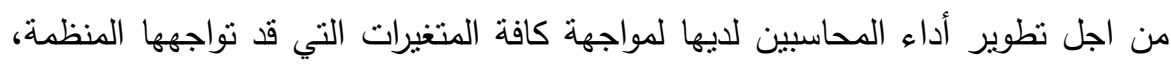

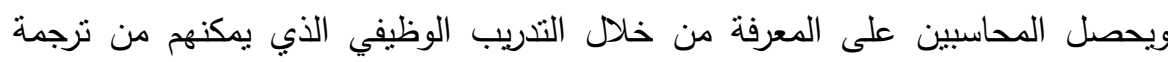

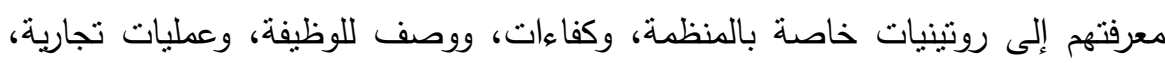

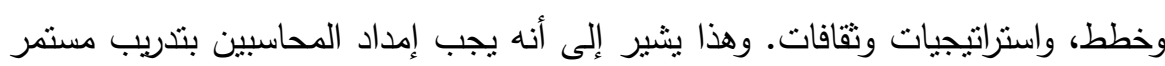

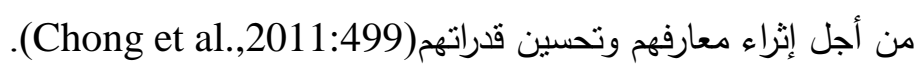
يذكر (Salleh et al., 2012: 167) انه يجب أن ينم توعية المحاسبين بعملية نقل المعرفة والخطة الثاملة لإدارة المعرفة من خلال التدريب على مستوى الإدارة.

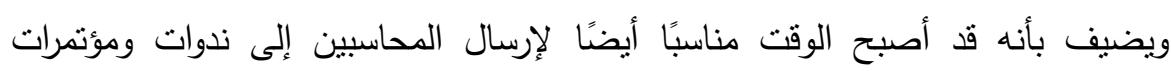
متعلقة بعطلية إدارة المعرفة من أجل تعزيز فهمهم لطريقة إدارة المعرفة في مجال الإنسال

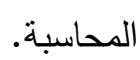
ويمكن القول أن حضور المحاسبين للندوات والمؤتمرات تخصصاتها وبشكل

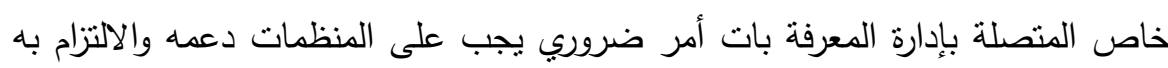

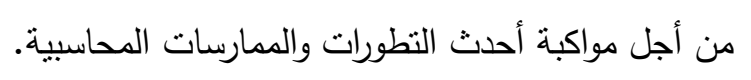

r-مفهوم القيادة الاستراتيجية للتعلم وعلاقة ودور المعرفة المحاسبية في كفاءتها.

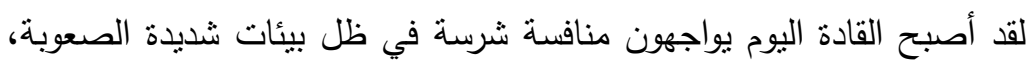

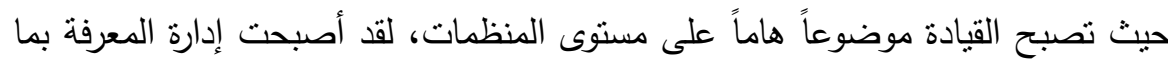

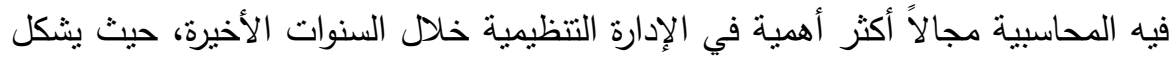

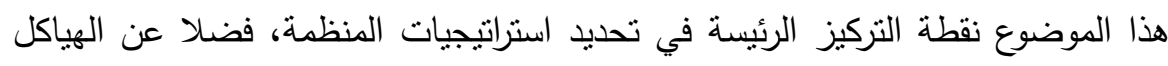

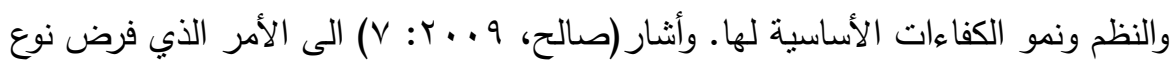


من الرواج أو التداخل بين واجبات المحاسب ومهامه من وظائف الإدارة وكيف يمكن للمحاسبة من دعم قيادة إستراتيجية المنظمة.

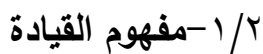

القيادة هي المدى الذي تفكر به المنظمة بشكل استراتيجي حول التعلم وخلق التغيير (Bozdogan, 2013: 126) )

وتثير القيادة الاستراتيجية إلى القدرة على التأثنر على الاخرين للاتخاذ الطوعي

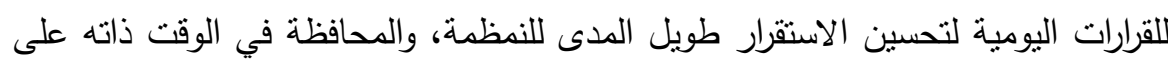

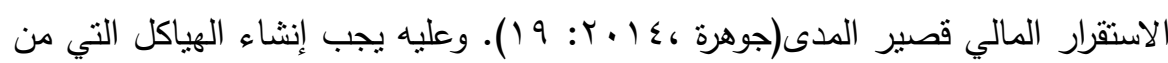

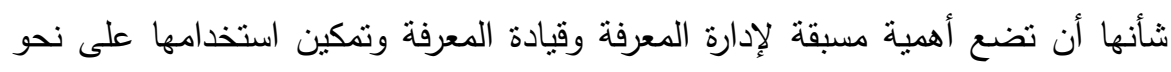
فعال في نظام المعرفة المحاسبية، ويمكن أن يكون هذا ممكنا فقط إذا قام إدام مديرين

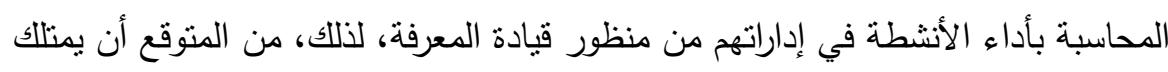

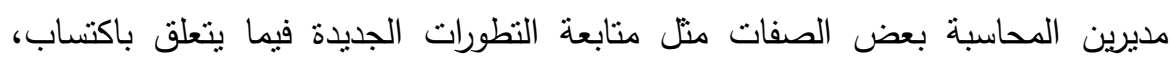

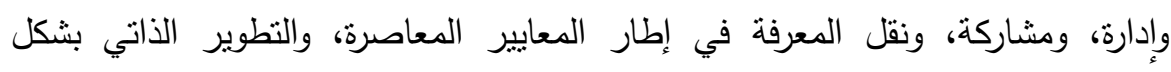

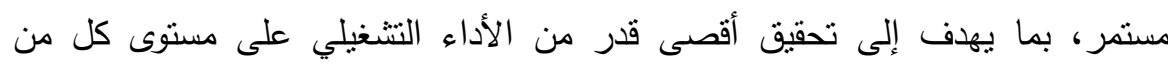

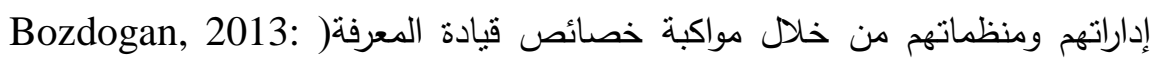

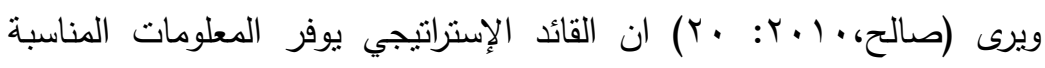

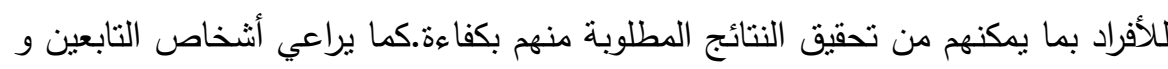

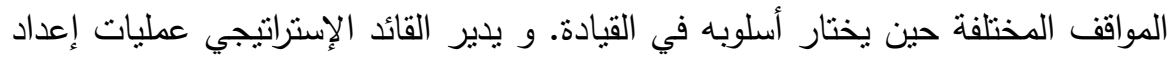
و إدارة و تتمية الموارد البشرية في منظومة منجانسة تعكس الاهتمامات الإستراتيجية للمنظمة و منطلبات تطويرها. ويؤكد (Chong et al, 2011 (499) إن التنفيذ المستقبلي لإدارة المعرفة في

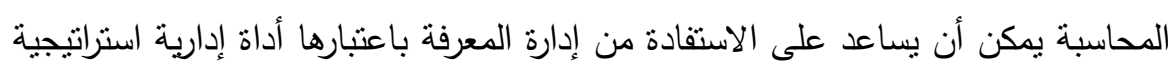

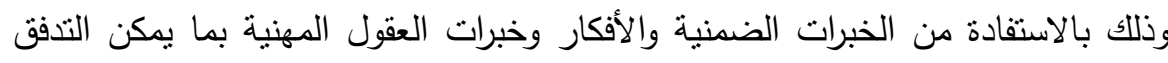

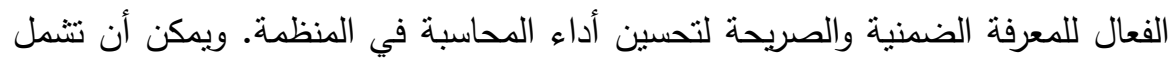
نتائج التحسن كل من عملية المحاسبة، وممارسة إعداد التقارير المالية، ونوعية عملية 
صنع القرار، وكذلك إثراء قيمة الأصول المعرفية أو رأس المال الفكري لقسم المحاسبة،

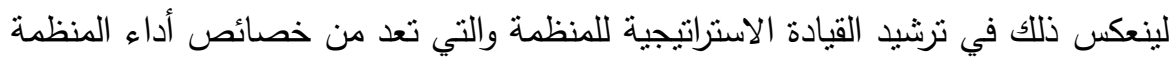

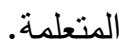

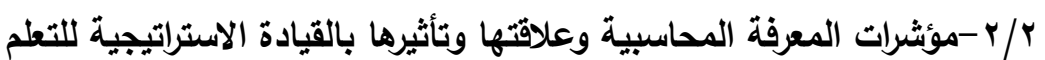

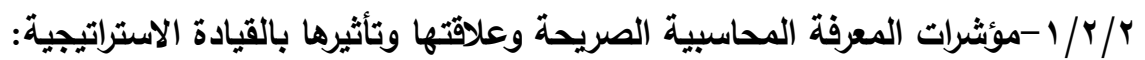
- الجوانب الفنية للمحاسبة: والتي نتنتمل التحديد، الاعتراف، القياس: نرتبط بترشيد

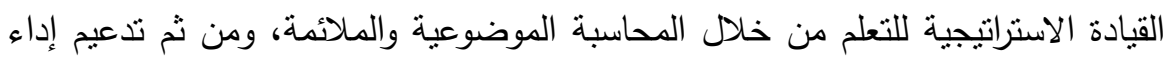

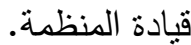
- الجوانب العلمية: معايير ومبادئ محاسبية: فمعايير التقدير السليم للإمكانيات المتاحة

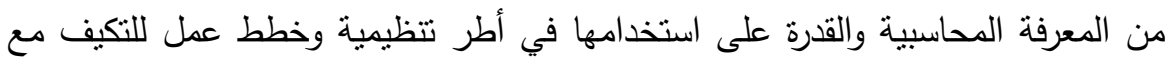

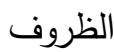
- الجوانب التطبيقية: وتتمثل بالإجراءات (الدورة المحاسبية): من خلال أسلوب بطاقة الأداء المنوازن تحقق تغيير جذري نحو توفير ما بحتاجه المديرين التتفيذيين لقيادة استراتيجية للتعلم في المنظمة - الجوانب الإعلامية: الإفصاح المحاسبي الداخلي (التقارير الداخلية): بعد وسيلة لدعم

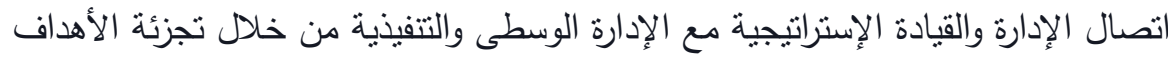

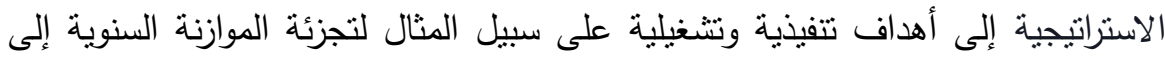
فصلية أو شهرية أو أسبوعية أو حتى يومية أو بالعكس الهن

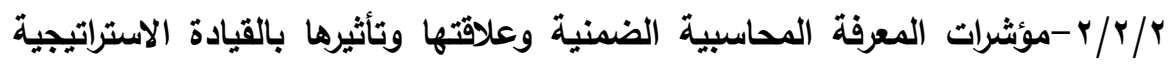

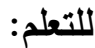
- العملية الإبداعية والابتكار المحاسبي: من خلال موائمتها مع رؤية وإستراتيجية

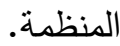
- المهارة المحاسبية: مهارة تقديم المعلومات المالية وغير المالية تستمدها الإدارة من محاسبيها لقيادة استراتيجيتها الخبرة المحاسبية: الخبرات المحاسبية تزود الإدارة برؤى استراتيجية من خلال توفير نمط

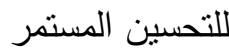


-التعلم المستمر: النطوير المحاسبي سيؤدي إلى مواكبة المحاسبة للابتكارات المحاسبة الاستراتيجية ومن ثم دعم القيادة بالمعلومات الاستراتيجية ب-اختبار الفروض

فيما يخص الفرض الرئيس الأول "لا نوجد علاقة ارتباط ذات دلالة إحصائية بين المعرفة المحاسبية والقيادة الاستراتيجية" ومن خلال التحليل الإحصائي لاستمارة

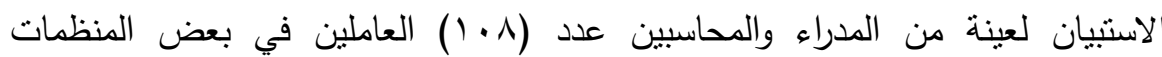
الصناعية العراقية وجد أن هناك بعض علاقات الارتباط المتفاوتة كما في الجدول (1)

$$
\text { الجدول(1) (1) }
$$

علاقة الارتباط بين جميع أبعاد المعرفة المحاسبية القيادة الاستراتيجية

\begin{tabular}{|c|c|c|c|c|c|c|c|c|c|}
\hline قيادة & مستعر & خبرة & مهارة & واببكار & إعلامية & علمية & تطبيقية & فنية & \\
\hline 1 & ${ }^{* *} \cdot$, , ^q & $*^{* *}, 0 \wedge r$ & ${ }^{* *},,\{0$. & ס*ז, & ${ }^{* *} \cdot$, \& & ${ }^{* *},, \circ \vee \varepsilon$ & ${ }^{* *} \cdot,\{v 1$ & ${ }^{* *} \cdot,\{19$ & قيادة \\
\hline
\end{tabular}

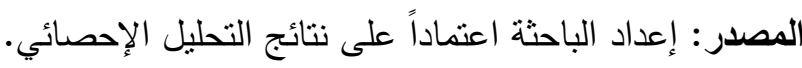
ويتضح من الجدول ما يلي: يتضح من الجدول أن عملية الإبداع والابتكار تمثل أعلى المتغيرات ارتباطاً بالقيادة

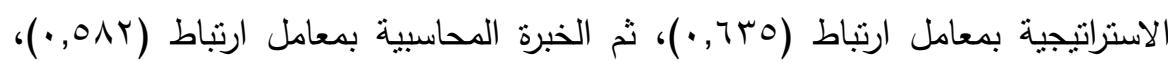

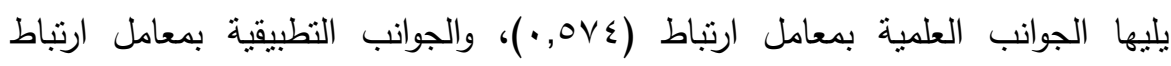

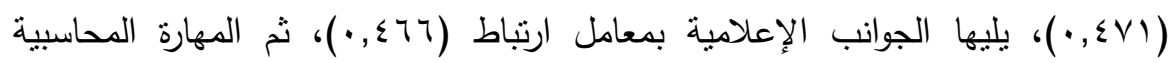

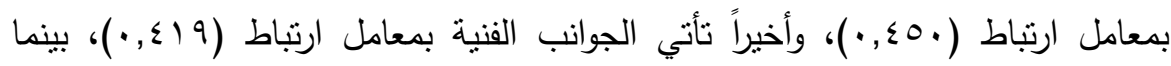

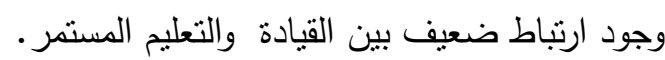

ويناء على النتائج السابقة يتضح رفض الفرض الرئيس الأول، وهذا يعني أنه "توجد

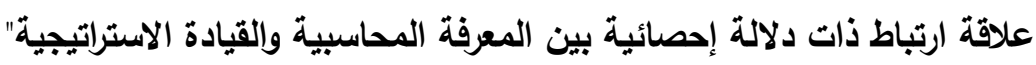
أما الفرض الرئيس الثاني فهو "لا يوجد تأثير ذو دلالة إنهائه إحصائية للمعرفة

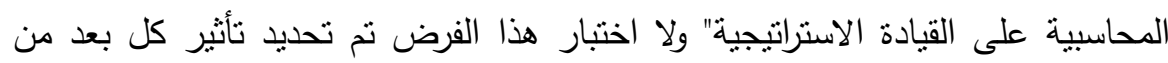
أبعاد المعرفة المحاسبية على القيادة الاستراتيجية كل على حدة، إذ قامت الباحثة بتقسيم الفرض الرئيس الثاني إلى مجموعة من الفروض الفرعية التالية: 
1- الا يوجد تأثثر ذو دلالة إحصائية للعملية الإبداعية والابتكار على القيادة الاستراتيجية. ץ-لا يوجد تأثير ذو دلالة إحصائية للخبرة الدحاسبية على القيادة الاستراتيجية.

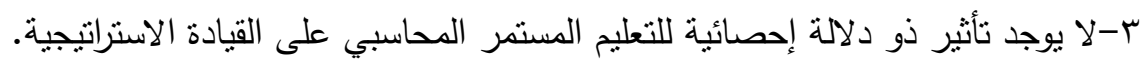
ع-لا يوجد تأثثر ذو دلالة إحصائية للمهارات المحاسبية على القيادة الاستراتيجية. ه-لا يوجد تأثثر ذو دلالة إحصائية للجوانب الفنية على القيادة الاستراتيجية. 1-لا يوجد تأثير ذو دلالة إحصائية للجوانب العلمية على القيادة الاستراتيجية. V-V لا يوجد نأثير ذو دلالة إحصائية للجوانب التطبيقية على القيادة الاستراتيجية. ^-لا يوجد تأثثير ذو دلالة إحصائية للجوانب الإعلامية على القيادة الاستراتيهية لإنية.

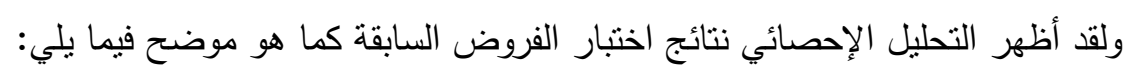

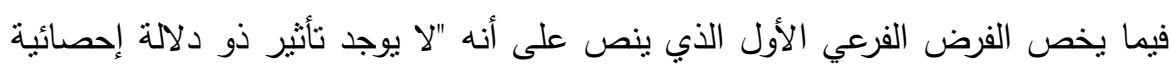

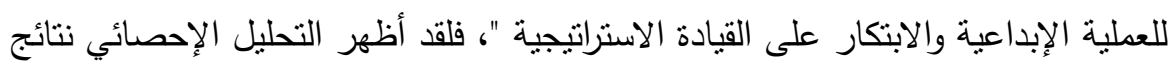
اختبارها كما هو موضح في الجدول (Y).

(r) الجدول (r)

نتائج تحليل تأثير العملية الإبداعية والابتكار على القيادة الاستراتيجية

\begin{tabular}{|c|c|c|c|c|c|}
\hline$\overline{\mathbf{R}^{2}}$ & $\begin{array}{c}\text { Adjust } \\
\text { ed } R^{2}\end{array}$ & $\overline{\text { B }}$ & (Sig)T & F (Sig) & المتغير \\
\hline$\cdot, \varepsilon \cdot \varepsilon$ & $\cdot, \Gamma \mu \wedge$ & ס ז7, & $\begin{array}{c}\wedge, \varepsilon \vee \cdot \\
(\cdot, \cdots)\end{array}$ & $\begin{array}{l}v 1, v \varepsilon \cdot \\
(\cdot, \cdots)\end{array}$ & الععلية الإبداعية \\
\hline
\end{tabular}

ويتبين من الجدول السابق ما يلي: والئيكار

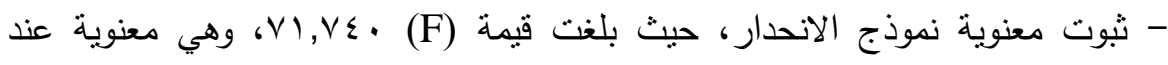

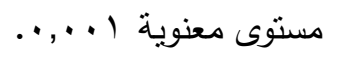

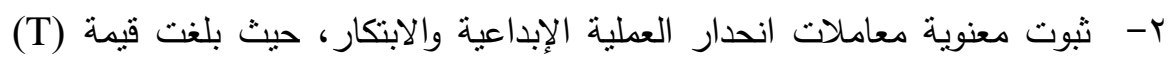

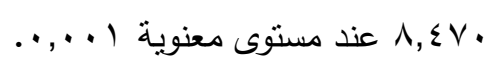

r- بلغت قيمة (B) مبآ, •، وهو ما يعني وجود تأثنر معنوي إيجابي للعملية الإبداعية

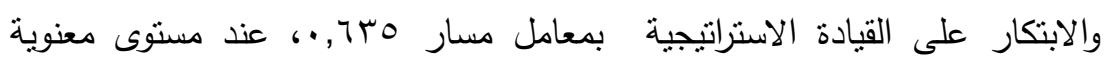
.., . 1

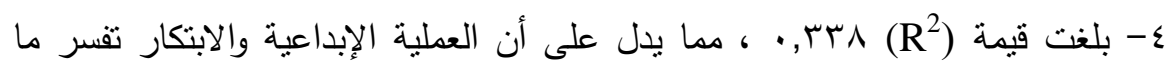

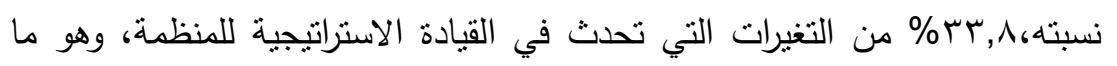


يعنى أنه كلما زادت مستويات العملية الإبداعية والابتكار ، كلما ارتفعت مستويات القيادة الاستراتيجية.

ويناء على النتائج السابقة يتضح رفض الفرض الفرعي الأول، وهذا يعني أنه " يوجد تأثير ذو دلالة إحصائية للعملية الإبداعية والابتكار على القيادة الاستراتيجية".

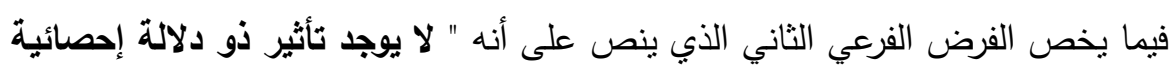
للخبرة المحاسبية على القيادة الاستراتيجية.

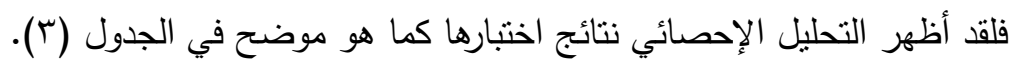

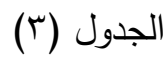

نتائج تحليل تأثير الخبرة المحاسبية على القيادة الاستراتيجية

\begin{tabular}{|c|c|c|c|c|c|}
\hline$\overline{\mathbf{R}^{2}}$ & $\begin{array}{c}\text { Adjusted } \\
\mathbf{R}^{2}\end{array}$ & $\bar{B}$ & (Sig)T & F (Sig) & المتغير \\
\hline$\cdot, r \mu q$ & • & $\cdot, O \wedge Y$ & $\begin{array}{c}v, r 70 \\
(\cdot, \cdots)\end{array}$ & $\begin{array}{l}0 \leqslant, Y \leqslant 0 \\
(\cdot, \cdots)\end{array}$ & المحاسبية \\
\hline
\end{tabular}

ويتبين من الجدول السابق ما يلي:

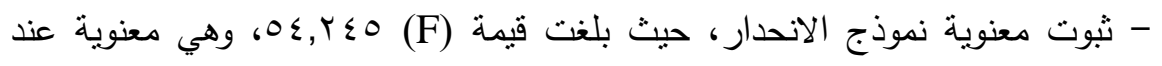
مستوى معنوية ل ل,,...

Y- ثبوت معنوية معاملات انحدار الخبرة المحاسبية والحد الثابت، حيث بلغت قيمة (T)

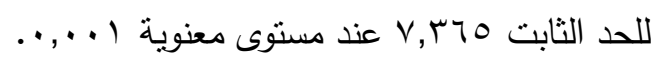

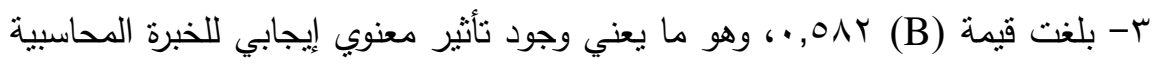

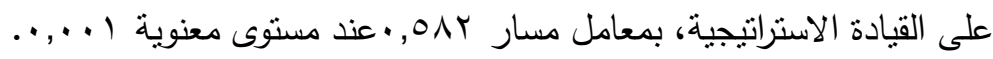

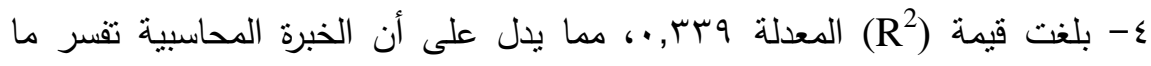
نسبته ؟r\% من التغيرات التي تحدث في القيادة الاستراتيجية، وهو ما يعنى أنه كلما زادت مستويات الخبرة المحاسبية، كلما ارتفعت مستويات القيادة الاستراتيجية. ويناء على النتائج السابقة يتضح رفض الفرض الفرعي الثاني، وهذا يعني أنه "يوجد تأثير ذو دلالة إحصائية للخبرة المحاسبية على القيادة الاستراتيجية ". 
وفيما يخص الفرض الفرعي الثالث الذي ينص على أنه " لا يوجد تأثير ذو دلالة إحصائية للتعليم المستمر المحاسبي على القيادة الاستراتيجية "، فلقد أظهر التحليل الإحصائي نتائج اختبارها كما هو موضح في الجدول (ع).

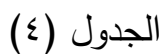
نتائج تحليل تأثير التعليم المستمر المحاسبي على القيادة الاستراتيجية

\begin{tabular}{|c|c|c|c|c|c|}
\hline$\overline{\mathbf{R}^{2}}$ & Adjusted $R^{2}$ & B & $\begin{array}{l}\text { (Sig) } \\
\end{array}$ & F (Sig) & المتغير \\
\hline$\cdot, \wedge$ & $\overline{\cdot, \cdot 1}$ & ·, $\wedge \wedge 9$ & $\begin{array}{l}r, 1 \cdot 0 \\
(, \ldots)\end{array}$ & $\begin{array}{l}q, 7 \leqslant \varepsilon \\
(\because \ldots r)\end{array}$ & التعليم المستمر \\
\hline
\end{tabular}
ويتبين من الجدول السابق ما يلي: - ثبوت معنوية نموذج الانحدار ، حيث بلغت قيمة (F) ـ ـ 1, 9، وهي معنوية عند مستوى معنوية ا.,.•. r- ثبوت معنوية معاملات انحدار التعليم المستمر المحاسبي والحد الثابت، حيث بلغت

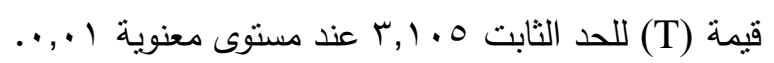

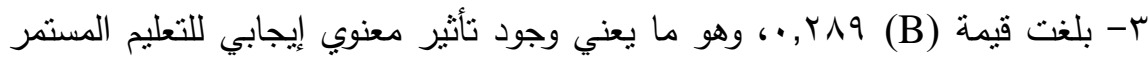

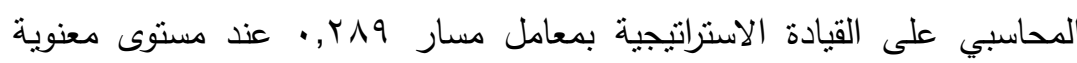
$\therefore, \cdot 1$

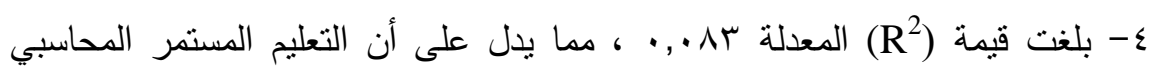

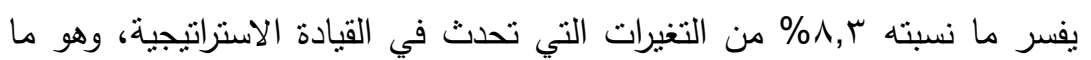

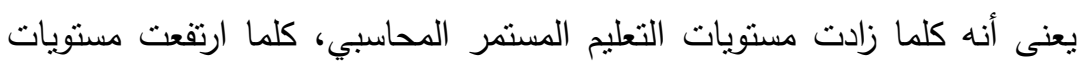
القيادة الاستراتيجية. ويناء على النتائج السابقة يتضح رفض الفرضة الفرض الفرعي الثالث، وهذا يغني أنه " يوجد تأثير ذو دلالة إحصائية للتعليم المستمر المحاسبي على القيادة الاستراتيجية". وفيما يخص الفرض الفرعي الرابع الذي ينص على أنه" لا يوجد تأثير ذو دلالة الفيانة إحصائية للمهارات المحاسبية على القيادة الاستراتيجية"، فلقد أظهر النحليل الإحصائي لإئي نتائج اختبارها كما هو موضح في الجدول (0).

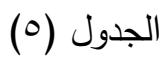
نتائج تحليل تأثير المهارات المحاسبية على القيادة الاستراتيجية 


\begin{tabular}{|c|c|c|c|c|c|}
\hline $\mathbf{R}^{2}$ & $\begin{array}{c}\text { Adjuste } \\
\mathbf{d ~ R}^{\mathbf{2}}\end{array}$ & B & (Sig)T & F (Sig) & المتغير \\
\hline$\cdot, r \cdot r$ & $\cdot, 190$ & $\cdot, \leqslant 0$. & $\begin{array}{c}0,1 \wedge . \\
(\cdot, \cdots r)\end{array}$ & $\begin{array}{l}r 7, q) 1 \\
(\cdot, \cdots)\end{array}$ & المحاسبية \\
\hline
\end{tabular}

ويتبين من الجدول السابق ما يلي:

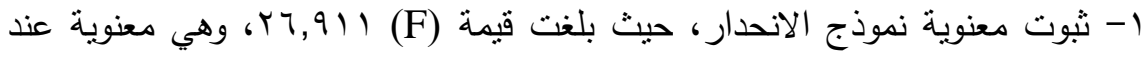

$$
\text { مستوى معنوية | +.,... }
$$

ץ- ثبوت معنوية معاملات انحدار المهارات المحاسبية والحد الثابت، حيث بلغت قيمة

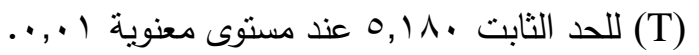

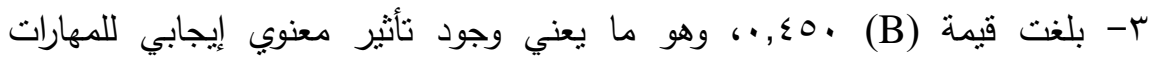

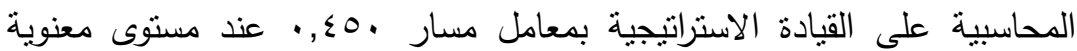
$\cdot \cdot, \cdots)$

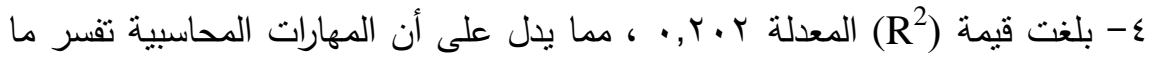

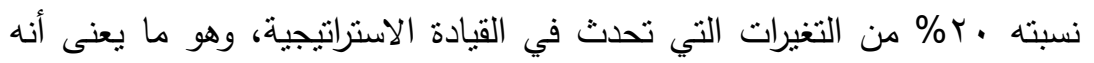

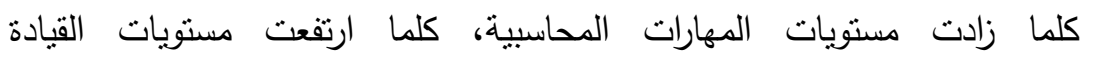

$$
\text { الاستراتيجية. }
$$

ويناء على النتائج السابقة يتضح رفض الفرض الفرعي الرابع، وهذا يعني أنه " يوجد

تأثثير ذو دلالة إحصائية للمهارات المحاسبية على القيادة الاستراتيجية ". فيما الفرض الفرعي الخامس الذي ينص على أنه " لا يوجد تأثير ذو دلالة إحصائية للجوانب القتية على القيادة الاستراتيجية "، فلقد أظهر التحليل الإحصائي نتائج اختبارها كما هو موضح في الجدول (T).

(7) (7) الجدول)

\begin{tabular}{|c|c|c|c|c|c|}
\hline$\overline{\mathbf{R}^{2}}$ & Adjusted $\mathbf{R}^{2}$ & B & (Sig)T & F (Sig) & المتغير \\
\hline$\cdot, 17 V$ & $\cdot, 171$ & $\cdot, 519$ & $\begin{array}{l}\varepsilon, Y O Y \\
(\because, \varepsilon O)\end{array}$ & $\begin{array}{l}r r, O V T \\
(, \ldots)\end{array}$ & الجو انب الفنية \\
\hline
\end{tabular}

نتائج تحليل تأثنير الجوانب الفنية على على القيادة الاستراتيجية

وينبين من الجدول السابق ما يلي: 
- ثبوت معنوية نموذج الانحدار ، حيث بلغت قيمة (F) F,OVT Y وهي معنوية عند

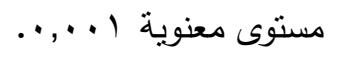

ب- ثبوت معنوية معاملات انحدار الجوانب الفنية والحد الثابت، حيث بلغت قيمة (T)

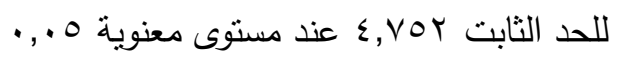
r- بلغت قيمة (B) 9 (اء,، ، وهو ما يعني وجود تأثثر معنوي إيجابي للجوانب الفنية

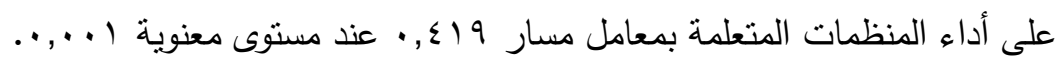

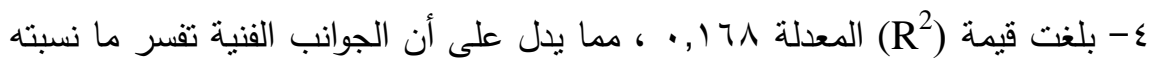

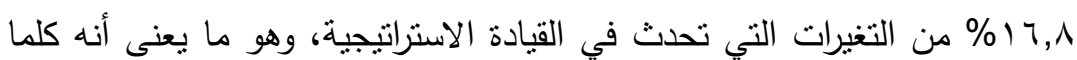

زادت مستويات الجوانب الفنبة، كلما ارتفعت مسنويات كفاءة القيادة الاستراتيجية.

ويناء على النتائج السابقة يتضح رفض الفرض الفرعي الخامس، وهذا يعني أنه " يوجد تأثير ذو دلالة إحصائية للجوانب القنية في القيادة الاستراتيجية ".

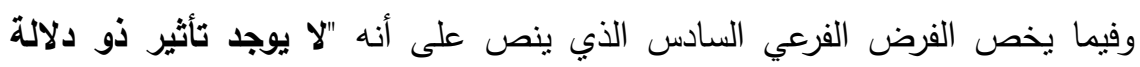
إحصائية للجواتب العلمية على القيادة الاستراتيجية "، فلقد أظهر التحليل الإحصائي نتائج اختبارها كما هو موضح في الجدول (V).

(v) الجدول

نتائج تحليل تأثثر الجوانب العلمية على القبادة الاستراتيجية

\begin{tabular}{|c|c|c|c|c|c|}
\hline$\overline{\mathbf{R}^{2}}$ & $\begin{array}{c}\text { Adjusted } \\
\mathbf{R}^{2}\end{array}$ & B & (Sig)T & F (Sig) & المتغير \\
\hline$r$ & $\overline{r, T Y Y}$ &., $0 \vee 7$ & $(\cdot, \cdots)^{\vee}, r^{10}$ & $(\cdot, \cdots)$ & الجوبية \\
\hline
\end{tabular}

المصدر: إعداد الباحثة اعتماداً على نتائج التحليل الإحصائي ويتبين من الجدول السابق ما يلي:

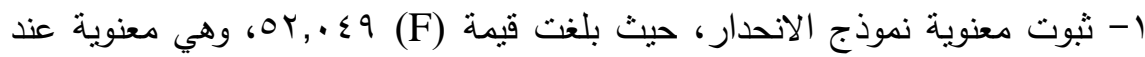

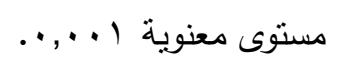

r) ثبوت معنوية معاملات انحدار الجوانب العلمية والحد الثابت، حيث بلغت قيمة (T) للحد الثابت V,Y 0 عند مستوى معنوية ل ..,... 


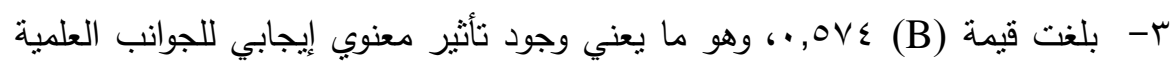

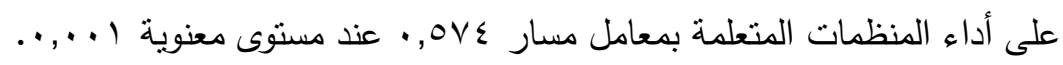

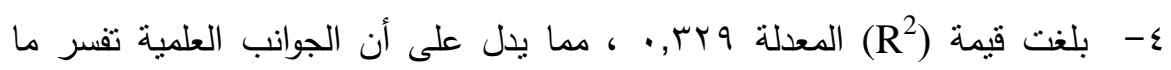

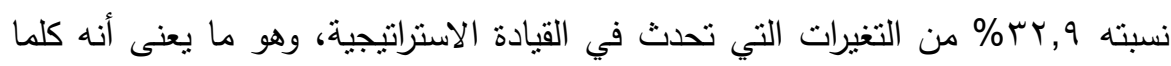
زادت مستويات الجوانب العلمية، كلما ارتفعت مسنتويات القيادة الاستراتيجية.

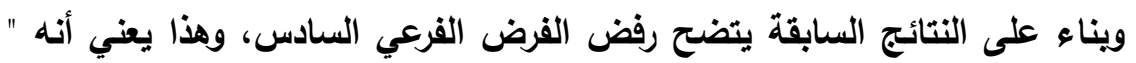
يوجد تأثير ذو دلالة إحصائية للجوانب العلمية على القيادة الاستراتيجية ".

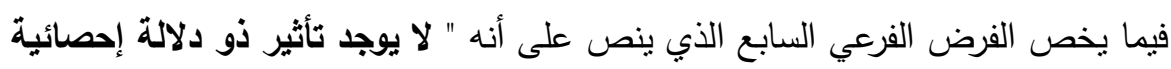
للجوانب التطبيقية على القيادة الاستراتيجية "، فلقد أظهر التحليل الإحصائي نتائج اختبارها كما هو موضح في الجدول (^).

(^) الجدول

نتائج تحليل نأثير الجوانب التطبيقية على القيادة الاستراتيجية

\begin{tabular}{|c|c|c|c|c|c|}
\hline$\overline{\mathbf{R}^{2}}$ & $\begin{array}{c}\text { Adjusted } \\
\mathbf{R}^{2}\end{array}$ & $\bar{B}$ & (Sig)T & F (Sig) & المتغير \\
\hline$\cdot, Y Y Y$ & $\cdot, Y) \varepsilon$ & $\cdot, \leqslant \vee 1$ & $\begin{array}{c}0, \leqslant 90 \\
(\cdot, \cdots 1)\end{array}$ & $\begin{array}{l}r \cdot, 191 \\
(\cdot, \cdots)\end{array}$ & التطبوانبة \\
\hline
\end{tabular}




$$
\text { ويتبين من الجدول السابق ما يلي: }
$$

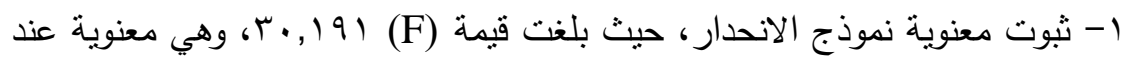

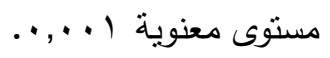

r- ثثوت معنوية معاملات انحدار الجوانب التطبيقية والحد الثابت، حيث بلغت قيمة

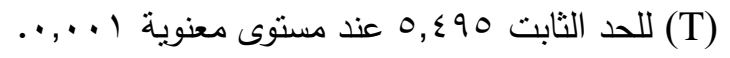

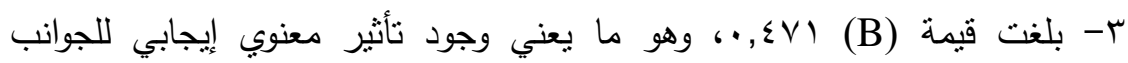

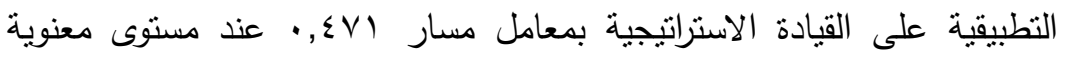

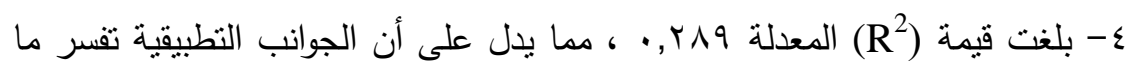

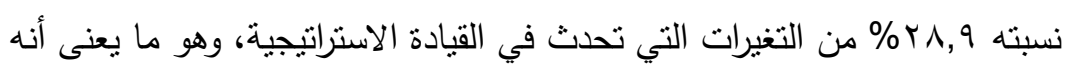

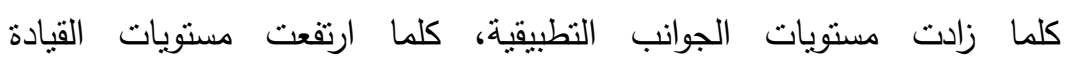

$$
\text { الاستراتيجية. }
$$

ويناء على النتائج السابقة يتضح رفض الفرض الفرعي السابع، وهذا يعني أنه " يوجد تأثير ذو دلالة إحصائية للجوانب التطبيقية في القيادة الاستراتيجية ".

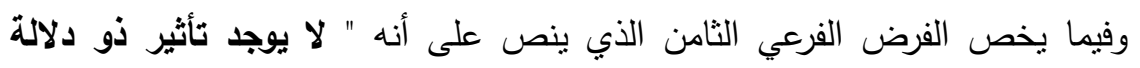
إحصائية للجوانب الإعلامية على القيادة الاستراتيجية "، فلقد أظهر التحليل

\begin{tabular}{|c|c|c|c|c|c|}
\hline$\overline{\mathbf{R}^{2}}$ & $\begin{array}{l}\text { Adjusted } \\
\mathbf{R}^{2}\end{array}$ & B & (Sig)T & F (Sig) & المتغير \\
\hline$\cdot, Y \backslash V$ & $\cdot, r \cdot q$ & $\cdot, \leqslant 77$ & $\begin{array}{c}0, \xi \backslash \wedge \\
(\cdot, \cdots)\end{array}$ & $\begin{array}{l}r q, r 07 \\
(\cdot, \cdots)\end{array}$ & الإعلامية \\
\hline
\end{tabular}

الإحصائي نتائج اختبارها كما هو موضح في الجدول (9).

(9) الجدول

نتائج تحليل نأثير الجوانب الإعلامية على القيادة الاستراتيجية

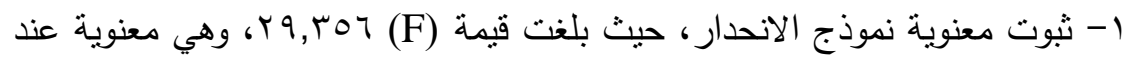

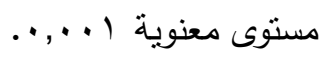

$r$. 
r- ثبوت معنوية معاملات انحدار الجوانب الإعلامية والحد الثابت، حيث بلغت قيمة

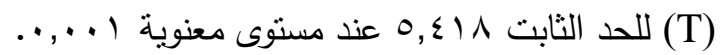

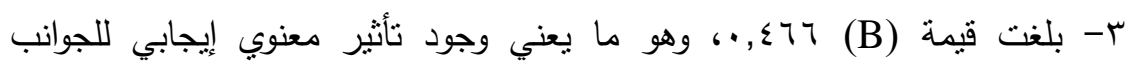

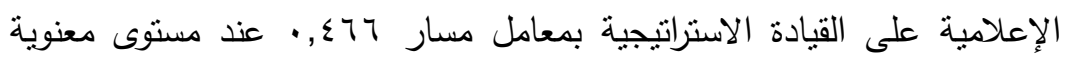

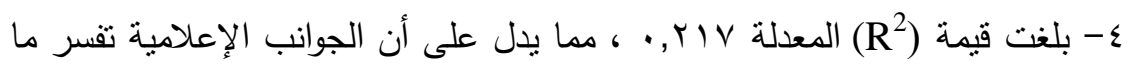

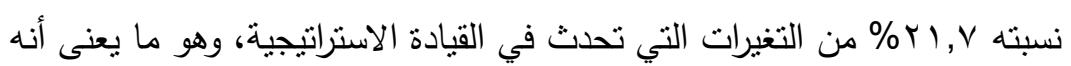

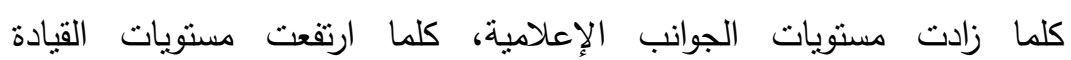
الاستراتيجية.

فيما يخص الفرض الرئيس الذي ينص على أنه " لا يوجد هناك أثر ذو دلالة إحصائية

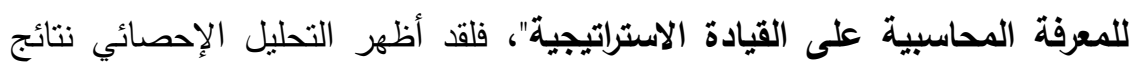
اختبارها كما هو موضح في الجدول (· (1).

$$
\text { الجدول (·) (1) }
$$

\begin{tabular}{|c|c|c|c|c|c|}
\hline$\overline{\mathbf{R}^{2}}$ & $\begin{array}{c}\text { Adjusted } \\
\mathbf{R}^{\mathbf{2}}\end{array}$ & $\frac{\text { على القة }}{\text { B }}$ & $\frac{\text { رفة المحاس }}{\text { (Sig)T }}$ & F (Sig) & المتغير نتائ. \\
\hline$\cdot, \leqslant 9$. & $\cdot, \leqslant \wedge 0$ & $\cdot, \vee \cdots$ & $\begin{array}{l}1 \cdot, \cdot 9 \cdot \\
(\cdot, \cdots)\end{array}$ & $\begin{array}{l}\cdot 1, \wedge \cdot V \\
(\cdot, \cdots)\end{array}$ & المحاسبية \\
\hline
\end{tabular}

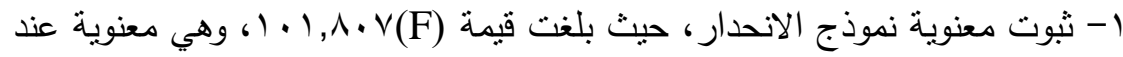

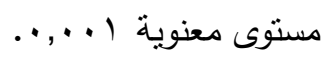

r- ثبوت معنوية معاملات انحدار المعرفة المحاسبية والحد الثابت، حيث بلغت قيمة

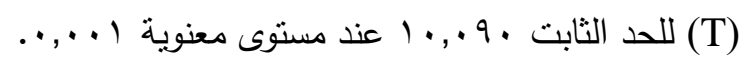

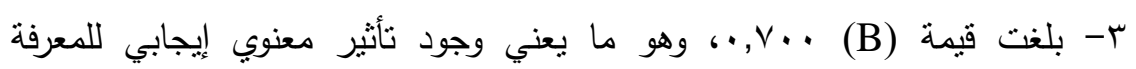

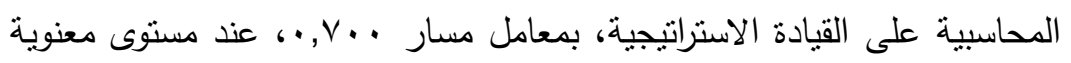




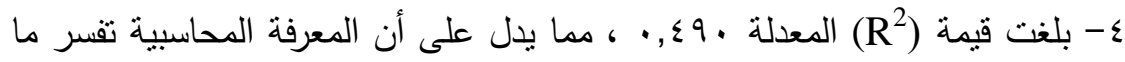

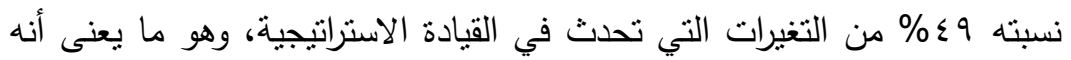

كلما زادت مستويات المعرفة المحاسبية، كلما ارتفعت مستويات القيادة

الاستراتيجية.

ويناء على النتائج السابقة يتضح رفض الفرض الرئيس، وهذا يعني أنه

يوجد هناك أثر ذو دلالة إحصائية للمعرفة المحاسبية على القيادة الاستراتيجية".

ع -النتائج والتوصيات

1/ 1 / النتائج

أ- لقد أكدت الدراسة أن المعرفة المحاسبية بمكوناتها الصريحة والضمنية أداة للقيادة

الاستراتيجية في المنظمات، فهي مصدر للميزة التتافسية من خلال تطبيقها في إدارة

المعرفة كأسلوب للخطط المستقبلية. وهي ذات تأثنر إيجابي ومباشر على أداء

القيادة الاستراتيجية للمنظمة.

ب- تعد المعرفة المحاسبية بمكوناتها المختلفة من المرتكزات الأساسية في التخطبط

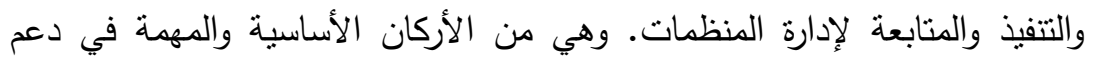

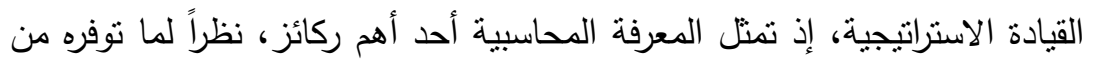

معارف تشكل القاعدة المعرفية لصناع القرار .

/ / التوصيات

وفي ضوء نتائج الدراسة توصي الباحثة

- ضرورة تطبيق أسلوب للمعرفة المحاسبية (بناء قاعدة معرفية) بالمنظمات لتأثثره

الإيجابي في ترشيد القرارات ودعم أداء القيادة الاستراتيجية للخطط المستقبلية.

- ضرورة نوجيه المزيد من الدراسات والأبحاث نحو اختبار دور المعرفة المحاسبية بمختلف مكوناتها وتأثنرها على أداء المنظمات. 


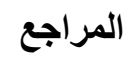

أولاً: المراجع العربية

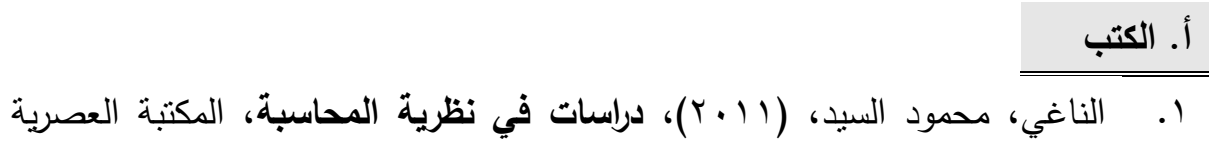

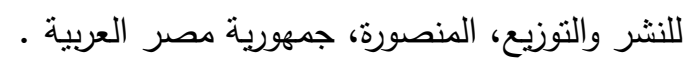

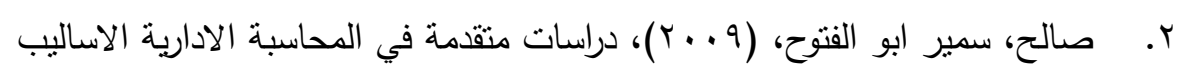

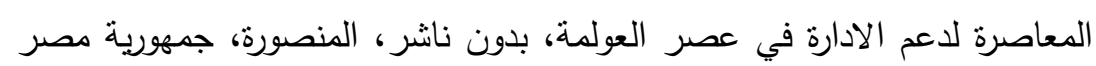

العربية.

ץ. محمود، صدام محمد، حسين، علي ابراهيم، (1) (ب)، المحاسبة ومواكبة التطور

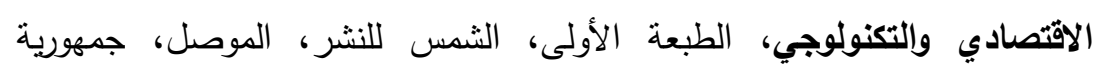

$$
\text { ب. الدوريات العلمية }
$$

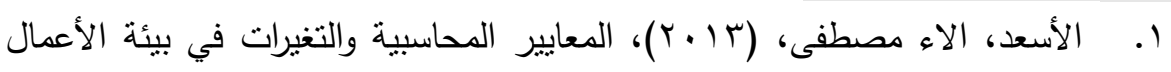

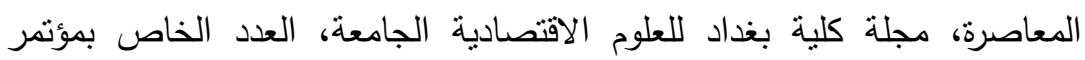

الكلية، كلية بغداد للعلوم الاقتصادية الجامعة، جمهورية العراق.

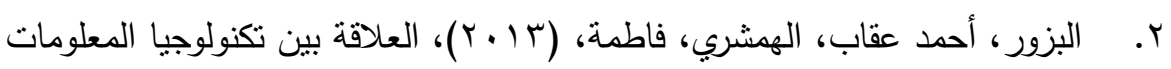

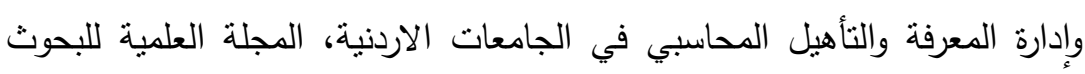

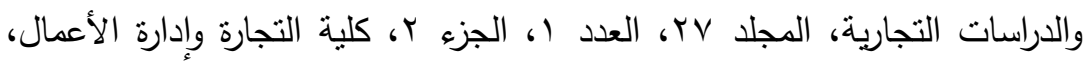

جامعة حلوان، جمهورية مصر العربية.

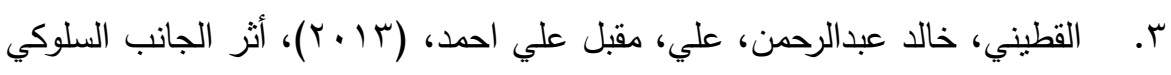

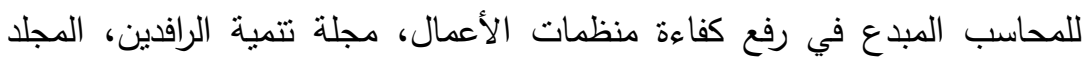

هr، العدد 1) (1، كلية الادارة الاقتصاد، جامعة الموصل، جمهورية العراق.

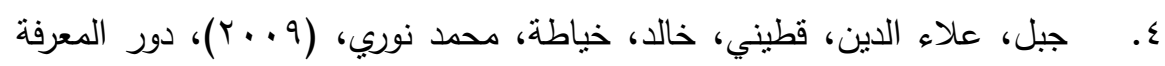

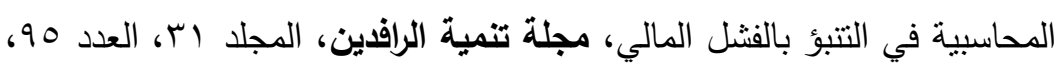

كلية الإدارة والاقتصاد، جامعة الموصل، جمهورية العراق. بالئل 


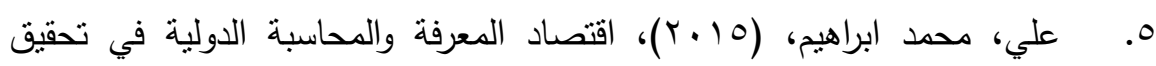
التتمية المستدامة دور تكامل اقتصاد المعرفة والمحاسبة الدولية في تحقيق التتمية

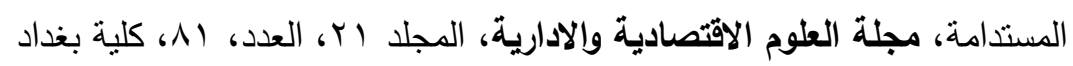
للعلوم الاقتصادية، جمهورية العراق.

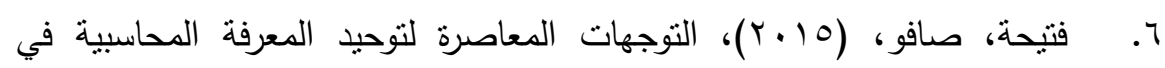

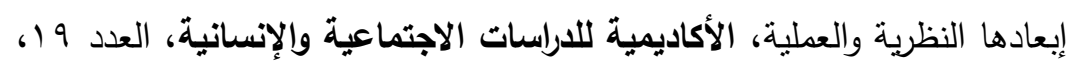
جامعة حسيبة بن بوعلي بالثلف، الجزائر .

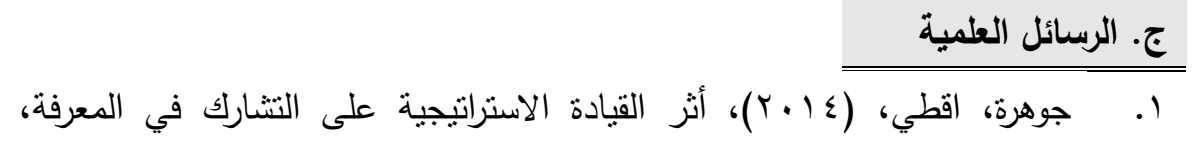
رسالة دكتوراه في علوم التسيير غير منثورة، جامعة بسكرة، الجزائر.

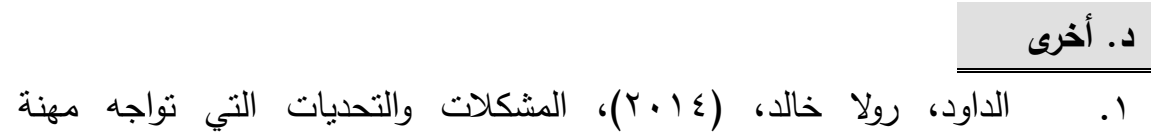
المحاسبة، المؤتمر العربي السنوي العام الأول، المنظمة العربية للتنمية

الإدارية، جامعة الدول العربية، جمهورية العراق.

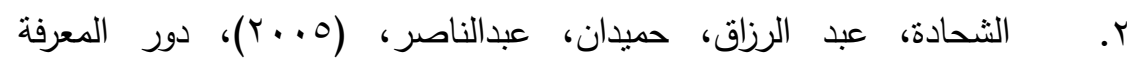

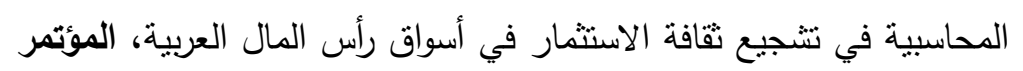

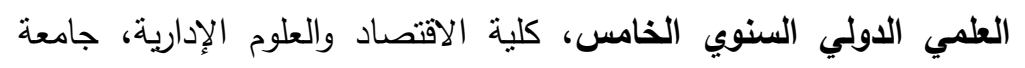
الزيتونة الأردنية، المملكة الأردنية الهاشمية.

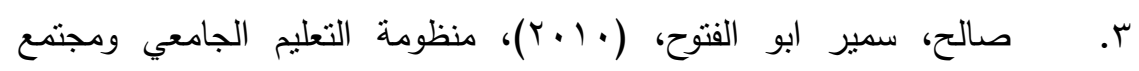

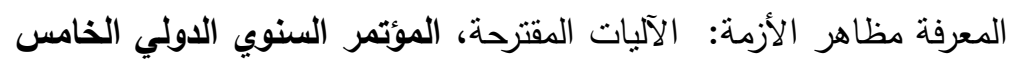
والعشرون، كلية التجارة، جامعة المنصورة، جمهورية مصر العربية. 


\section{B. Periodicals}

1. Abdelsalam, Omneya H. \& Weetman, Pauline, (2007), Measuring Accounting Disclosure in a Period of Complex Changes: The Case of Egypt Review Article, Advances in International Accounting, Volume 20, Pages 75-104.

2. Bozdogan, Tunga, (2013), a Research on Knowledge Leadership Characteristics in Accounting Department Managers in Turkey, International Journal of Business and Social Science, Volume 4, No. 14.

3. Chong, Siong Choy \& Salleh, Kalsom \& Syed Ahmad, Syed Noh \& Sharifuddin, Syed-Ikhsan Syed Omar, (2011), KM Implementation in a Public Sector Accounting Organization: an Empirical Investigation, Journal of Knowledge Management, Volume 15, Issue 3.

4. Mohamed, Ehab K.A., \& Lashine, Sherif H., (2003), Accounting Knowledge and Skills and The Challenges of a Global Business Environment, Managerial Finance, Volume 29, Issue7.

5. Salakjit, N., \& Phapruke, U., (2011), Accounting Professionalism, Financial Reporting Quality and Information Usefulness: Evidence From Exporting Firms in Thailand, Journal of International Business and Economics, Volume 11, Issue 4.

6. Salleh, Kalsom \& Chong, Siong Choy \& Syed Ahmad, Syed Noh \& Syed Ikhsan, Syed Omar Sharifuddin, (2012), Learning and Knowledge Transfer Performance Among Public Sector Accountants: an Empirical Survey, Knowledge Management Research \& Practice, Volume 10, No. 2.

7. Schiller, S., (2010), Management Accounting in a Learning Environment, Journal of Accounting \& Organizational Change, Volume 6, Issue 1.

\section{Thesis}

1. Anany, Tarek Y., (2011), The Impact of non Audit Services on Investor Perceptions of Auditor Independence, Auditor Knowledge and Audit Quality, the Master Doctor of accounting, Cairo University, Egypt.

2. Pitzer, Patricia Stone, (2007), a Knowledge Management Policy for a Learning Organization, the Master of Science, Faculty of California State University of Dominguez Hills, USA.

1. Gornjak, Mojca, (2014), Knowledge Management and Management Accounting, Work Paper, Presented at International Conference 25-27 June 2014, Portorož, Slovenia. 
ry 